\title{
Quality Improvement of Public Service of Automobile Transport: Economic Evaluation Method
}

\author{
Martynushkin A.B.* \\ Ryazan State Agrotechnological University Named \\ after Kostychev P.A. \\ Ryazan, Russia \\ e-mail: martinyshkin@mail.ru
}

\author{
Konkina V.S. \\ Ryazan State Agrotechnological University Named \\ after Kostychev P.A. \\ Ryazan, Russia \\ e-mail: konkina_v@mail.ru
}

\begin{abstract}
Analyzing the scientific literature in the field of methodology for evaluating the efficiency of passenger transport by road, it should be noted that the categories of efficiency in social and economic terms are interpreted ambiguously and require a certain compilation. Cost-effective offers are not necessarily those from the point of view of social efficiency, due to the fact that the desire to maximize the gross profit in the motor transport enterprise (namely, this is the main goal of the functioning of any commercial organization) can contribute to reducing the free time of an individual presenting a solvent demand for transport services, reducing the quality of passenger transport services, etc. It is necessary to take into account that the market for road transport of passengers on the scale of an entire region has many agents with often completely opposite interests. As a result, the methodology for calculating efficiency will differ for each of them. For commercial carriers, efficiency will be calculated as the ratio of financial results (revenue) and costs (cost). Local authorities need to ensure that transport services are physically and financially accessible to all segments of the population, while optimizing budget expenditures. For direct consumers of carriers ' services, the priority is the price and quality level of road transport services. From all the above, it should be noted that the methodology used to assess the overall level of efficiency of passenger road transport in the region should take into account the interests of all subjects of the transport services market. In the process of compiling this methodology, the authors took into account previously presented research in this area, quality calculation standards applied abroad, and passenger surveys. The main purpose of the presented method is to calculate the required social effect of passenger transport in the region, as well as the costs that need to be made to ensure it, and the income that will be received at a given level of service to the city's population. When calculating these indicators, the interests of each participant in the passenger transport market (municipalities, owners of private transport companies, and passengers) should be taken into account. Methodology. In the process of implementation of this work, such generally accepted methods as analysis and synthesis, comparisons and analogies were used. We conducted a survey of participants in the market under study. We extrapolated the data obtained for future periods. Results. Analyzed existing methods of estimation of efficiency of transportations of passengers in social and economic terms, given their weaknesses, the arguments confirming the necessity to consider new methods that would allow to fully assess the social and economic efficiency of road passenger transport. Job prospects. The analysis shows that there is an urgent need to develop methodological support in the field of quality assessment and improving the efficiency of passenger
\end{abstract}

transport management. In the presented methodology, the social effect of urban passenger transport is evaluated by the quality level of motor transport provision for passengers. This indicator should include both the quality characteristics of passenger service and the level of transport tariffs of different carriers, since for many categories of passengers the latter indicator will play a decisive role in choosing the category of vehicle and carrier.

Keywords - economic and social efficiency, passenger transportation, urban passenger transport, quality assessment, the quality of road transport services, estimated through an integral indicator.

\section{INTRODUCTION}

Nowadays automobile passenger transport is one of the most important components of the paid services provided to the population. It is difficult to overestimate the economic and social significance of passenger transportation, which has a great impact on the transport accessibility of regions, the level of transport mobility of the population and the welfare of citizens. Moreover, in the context of limited financing of municipal transport from local budgets, it becomes necessary to determine the optimal amount of investment in the development of the transport infrastructure of the city. Modern municipal passenger transport is unprofitable, therefore, even if compensation is received from the budget for the transportation of privileged passengers and cost containment, municipal transport enterprises still do not have enough funds to upgrade the rolling stock. It causes deterioration of passenger service. Sometimes such a situation occurs that all losses of motor transport enterprises are compensated at the expense of the budget, regardless of what caused these losses: providing benefits and restraining tariffs or simply inefficient work. Consequently, municipalities are interested in reducing losses. Currently, losses are increasing even more due to the outflow of passenger traffic to commercial motor transport enterprises (MTE), which offer a different (excellent) quality of the transportation process. As a result, it is advisable to calculate the level of transport provision for passengers, which allows you to form the required passenger flow. At the same time, the losses of municipal carriers should be reduced, and the volume of city budget investments should increase [1-3] In each urban MTE, the main task of organizing and planning the production process always becomes the optimal combination and use of all resources to perform maximum transport work and improve the quality of public service. 
Commercial enterprises are interested in maximizing their own profits as a factor of increasing the value of their business [4]. Moreover, they can achieve maximum profits by reducing the cost of passenger transportation, which may lead to deterioration in the service provided. A decrease in this indicator, in turn, can adversely affect the amount of passenger traffic. Therefore, it is also important for private motor transport enterprises to determine the optimal level of passenger service, which will ensure the maximum profit. $[5,6]$.

\section{LITERATURE REVIEW}

When assessing the socio-economic effect of the development of passenger transport, one can judge by the following formula:

$$
E f=\left(C_{2}+E_{n} C E_{2}\right)-\left(C_{1}+E_{n} C E_{1}\right)+E f_{c h}\left(T_{1}-T_{2}\right),(1)
$$

where $C E_{1}$ is capital expenditures;

$$
C_{1} \text { is operating expenditures (cost value); }
$$

$T_{1}$ is time spent by the population when the initial transport variant;

$C E_{2}, C_{2}, T_{2}$ are accordingly, with a better quality variant of transport;

$E_{\mathrm{n}}$ is the norm coefficient of efficiency of investments;

$E f_{\text {ch }}$ is the socio-economic effect of customer hour.

In this case, the following conditions must be met $C_{2}+E_{n} C E_{2}>C_{1}+E_{n} C E_{1}$ and $T_{1}>T_{2}$, i.e. the first variant is cheaper, and the second one is faster.

In this case improvement of passenger transportation is under review justified in the socio-economic plan, provided:

$$
\frac{\left(C_{2}-C_{1}\right)+E_{n}\left(C E_{2}-C E_{1}\right)}{T_{1}-T_{2}}<E f_{c h}
$$

Here, $E f_{\text {ch }}$ serves as the socio-economic standard for passenger efficiency.

A similar approach can be applied to other valued social factors of passenger transport efficiency. [7, 8]

Some scientists suggest determining the socio-economic effect of bus transport according to the following relationship:

$$
E_{s e}=Q \times k \pm W_{t}-A
$$

where: $Q$ is the income from passenger traffic in the reporting period (in rubles);

$W_{\mathrm{t}}$ is the economic assessment of the time of passengers additionally saved (spent) by them (rubles);

$A$ is the economic assessment of road accident losses (rubles);

$k$ is a comprehensive coefficient of service quality, which is determined by the following formula:

$$
k=\frac{k_{1}+k_{2}+k_{3}}{3},
$$

where: $k_{1}$ is the number of complaints from the population in the period under review compared with the base period (average for 3 years);

$k_{2}$ is a coefficient of service quality at bus stations (estimated in points; max value is 1 );

$k_{3}$ is a coefficient of provision of pavilions of extra-urban routes and stops in cities with timetables and interval tables; (at least 100 stops and pavilions or at least $25 \%$ of the total number in the MTE service area are examined).

At the same time, $Q \times k$ expresses the population's satisfaction with transportation, taking into account its quality.

In a case of trip interruptions, $W_{\mathrm{t}}$ is determined as follows:

$$
W_{t}=t_{p} E f_{c h} T_{f} q_{f},
$$

where $t_{c}$ is extra time spent per passenger (hour);

$E f_{c h}$ is customer-hour economic assessment (rubles);

$T_{f}$ is the number of failure in linear time (hour) due to disruptions);

$q_{f}$ is the average number of passengers per 1 hour of linear time.

If it is late for the economic assessment of the time additionally spent by passengers, one can use the formula:

$$
W_{t}=E f_{c h} \cdot q_{f} \cdot T_{f}
$$

where: $T_{f}$ is the total time of delays for the considered period (hour).

It should be emphasized that it is possible to save the passenger's time not only by increasing the speed of vehicles, but also by reducing the interval of movement and increasing the regularity of transport, better informing passengers about the schedules of vehicles, approaching stops on the way to the trip destination, etc. [3].

There is a methodology for assessing the efficiency of passenger vehicles at the city level, within which it is proposed to use:

1) an indicator of overall efficiency, which consists of the direct effect of a car enterprise, a concomitant effect (an effect obtained in other sectors of the national economy) and a social effect in the form of an additional fund of free time obtained by travel saving;

2) the indicator of passenger turnover, which allows determining the main directions of development of passenger transport. [9]

The authors also propose to add performance indicators of auto enterprises to the methodology for assessing the efficiency of passenger vehicles at the city level. [10,11]

Let us consider a technique in more detail. 
The overall effect at the city level $\left(E f_{\text {total }}\right)$ is determined by the following formula:

$$
E f_{\text {total }}=E f_{\text {direct }}+E f_{\text {spill }}+E f_{\text {soc }},
$$

where $E f_{\text {direct }}$ is direct effect resulting from the economic activities of MTE;

$E f_{\text {spill }}$ is the spillover effect detected in enterprises serviced by passenger transport;

$E f_{s o c}$ is social effect in terms of the cost of reducing the travel time of passengers.

Further, in order to determine the efficiency of intercity passenger vehicles, this overall effect must be compared with expenditures (Exp) incurred, which are proposed to be determined by the following formula:

$$
E_{x p}=C+E_{n}+C E
$$

where $C$ is current costs (rubles/year);

$C E$ is capital expenditures (rubles);

$E_{n}$ is the normative efficiency coefficient.

It is necessary to include environmental costs in additional capital investments for the expansion and replacement of passenger vehicles.

Returning to the determination of the overall effect of the activity of urban passenger transport, the proposed methods for determining its components are considered. [12]

The direct effect refers to the rational use of all available resources of the automobile company. In general, it is determined by the following formula:

$$
E f_{\text {direct }}=P_{f}-P_{p l},
$$

where $P_{f}$ and $P_{p l}$ are the economic results of the automobile company are the profit (actual and planned) and if a passenger MTE is unprofitable, then the planned result has a "_" sign).

The improvement of the work of intercity passenger vehicles directly affects the amount of free time. Free time is a part of the total time fund that a person has. It is obvious that the shorter the duration of the trip, the more time for professional development, recreation, and social development. Thus, the social effect of the functioning of the MTE can be defined as a reduction in the passengers travel time, both in cost and in-kind estimation:

$$
E f_{s o c}=C E s \times N \times \bar{t},
$$

where $C E s$ is the estimated value of 1 hour of free time (rubles per person/hour);

$N$ is the annual number of passengers transported (persons);

$t$ is the average reduction in trip duration per 1 passenger.

However, there are certain difficulties in determining the cost of a passengers free time.
The average trip reduction time is calculated as the difference between the actual time spent on a trip to work and the standard for such movements.

The improvement of the service in the intercity passenger transport leads to reduced transport fatigue, which reduces disease incidence of passengers and causes a concomitant economic effect: increased labor productivity, reduced rejects and improved product quality in the field of material production $[14,15]$.

As a result of many sociological studies, a direct dependence of the level of labor productivity on conditions of passenger transportation was determined. Thus, the concomitant effect of improving the work of urban passenger transport should include an increase in output at city enterprises as a result of a decrease in transport fatigue of employees of enterprises and a decrease in staff turnover. In the framework of the proposed methodology, the concomitant effect is estimated as follows:

$$
E f_{\text {spill }}=W \times R \times D \times K_{1} \times K_{2} \times K_{3},
$$

where $W$ is the average daily output of one worker;

$R$ is the number of workers using urban passenger transport;

$D$ is the average number of working days per worker;

$K_{1}$ is a coefficient taking into account the number of employees who are subject to transport fatigue;

$K_{2}$ is a coefficient taking into account the decrease in the average daily output of one worker as a result of transport fatigue;

$K_{3}$ is the average profitability of products.

Now it is necessary to return to the passenger turnover indicator characterizing the degree of using the passenger compartment capacity and the quality of passenger service.

In the formulas for calculating the passenger turnover indicator, there is a close functional relationship between the studied indicator and the factors influencing it. At the same time, the arrangement of factors is essential, since a change in their order leads to violation of the logical connection and a change in the degree of influence of each factor on the passenger turnover. Among the authors involved in calculating the passenger turnover indicator, there is no unity in the arrangement of factors.

Some places these factors in the following order:

$$
P=T_{h} \times M_{\text {tot }} \times \beta \times q_{a} \times \gamma_{\text {cap }} \times N_{b} \times \alpha \times D_{e}
$$

Other researchers have the same factors in the following way:

$$
P=N_{b} \times D_{e} \times \alpha \times T_{h} \times M_{\text {tot }} \times q_{a} \times \gamma_{c a p} \times \beta
$$

In the methodology developed by the St. Petersburg Department of Passenger Transport, the sequence of factors was adopted as follows: 


$$
P=D_{e} \times N_{b} \times \alpha \times T_{h} \times M_{\text {tot }} \times q_{a} \times \gamma_{c a p} \times \beta .
$$

Summarizing the above, it is more expedient to propose the following sequence of factors:

$$
P=N_{b} \times D_{e} \times \alpha \times T_{h} \times M_{\text {tot }} \times \beta \times q_{a} \times \gamma_{c a p},
$$

where $N_{b}$ is the number of buses;

$D_{e}$ is bus days at the enterprise;

$\alpha$ is bus days at work;

$T_{h}$ is bus hours at work;

$M_{t o t}$ is total mileage;

$\beta$ is useful mileage;

$q_{a}$ is the full bus capacity;

$\gamma_{c a p}$ is the use of bus capacity.

It can be concluded that there is currently no single methodology for assessing the socio-economic efficiency of urban public transport.

The analysis of existing methods for assessing the quality of transport service allows concluding that among them there is no one that would fully meet the existing conditions in the market for passenger transportation. Disadvantages of existing methods for assessing the quality of transport service for the population of the region (one or more of the listed below) are as follows.

1. They propose evaluating the quality of transport service using only one indicator, which is very problematic, if not practically impossible.

2. They are characterized by the subjectivity of the assessment. This is due to the fact that to assess the quality of transport service, indicators that are not calculated or cannot be quantified are used. In these cases, it is proposed to use expert assessment methods, which are characterized by a certain degree of subjectivity.

3. When determining the integral indicator of the quality of transport service, some methods do not take into account the validity of each individual quality indicator. This leads to the fact that the unsatisfactory value of some indicators characterizing the quality is compensated by other indicators, and this should be absent. [13]

4. They do not take into account the real interests and needs of passengers, especially since these needs have changed significantly lately.

5. The main part of the analyzed methods was developed in the period when the passenger transport market did not have such a large number of private owners yet. Thus, many of these methods can not be used to evaluate the performance of private carriers. This is due to the fact that private carriers, especially those that own one vehicle, do not have much of the data necessary to calculate these coefficients.
Therefore, an improved methodology for assessing the quality of transport service is required. It will eliminate all the above disadvantages, take into account all the main indicators characterizing the quality of transport service and will allow getting the most objective assessment [5].

\section{METHODOLOGY}

In the process of developing this methodology, we used statistical data in the field of road transport economics both in Russia as a whole and in the Ryazan region in particular, as well as data from the Ryazan city transport administration.

Common methods such as analysis and synthesis, comparisons and analogies were used. We conducted a survey of participants in the market under study. We extrapolated the data obtained for future periods. We used factor analysis of the financial condition of the enterprise.

\section{ASSESSMENT METHODOLOGY}

Based on the economic situation prevailing in the market of municipal passenger transportation, it should be concluded that a compromise must be found between the participants. For this, it is necessary to determine the optimal level of quality of passenger transport service and the costs associated with them, which would suit all participants [16].

The following algorithm is proposed:

1. The development of a methodology that would allow assessing the level of transport service in the region.

The modern methodology for assessing social and economic efficiency of urban public transport should be a comprehensive system of indicators, on the basis of which it would be possible to determine the effectiveness of activities of a single enterprise, regardless of ownership, and the effectiveness of transport service in the region as a whole. The system of these indicators should reflect the degree of satisfaction of the needs of passengers and society as a whole, as well as an increase in service per unit of cost while improving their quality characteristics and an increase in revenues of motor transport enterprises per unit of service.

In order to determine the present level of passenger service, it is necessary to use an integral indicator based on a number of particular indicators. This is due to the fact that it is rather difficult to assess the level of quality of a service using only one characteristic. It is necessary to take into account the validity of each particular indicator, while remembering that the validity of each particular indicator can vary depending on the population group, travel goals and time.

2. Determining the relationship between the level of passenger transport service and the costs that are necessary to ensure it.

3. Determining the relationship between passenger transportation and the level of passenger service. In general, the level of service affects the number of passengers using this type of transport (passenger traffic). However, there is a certain share of passenger traffic that does not depend on the level of service. Passenger traffic, in turn, has a direct impact on revenues received by road transport enterprises. Therefore, 
all income derived from the transportation of passengers can be divided into income from the sale of passenger service, provided that the passenger requirements for the level of service are not taken into account, and income that is caused by an increase in passenger traffic as a result of an increase in the level of passenger service.

It is advisable to consider the determination of relationships between the costs of providing passenger services and the level of transport services, as well as between the revenues from the sale of services and the level of service at the city or regional level, but in this case the average data will be obtained.

4. Determining the optimal level of passenger traffic quality.

Municipal city passenger transport is unprofitable. Losses from its activities are compensated from the municipal budget, often not in full. The chronic shortage of funds has a very negative impact on the competitiveness of municipal carriers and on the quality of their transport services. Therefore, the goal of municipalities will be to minimize losses [12]. Then the target function of municipalities can be represented as follows:

$$
\left\{\begin{array}{l}
\operatorname{Exp}-D \rightarrow \min \\
K \geq K_{\text {min }}
\end{array},\right.
$$

where $K$ is the level of passenger transport services by municipal transport;

$K_{\min }$ is the minimum acceptable level of transport services for the population of the city (region);

Exp is funds spent on the provision of transport services to the city-owned MTE, reflected depending on the quality of transport services to the population;

$D$ is revenues of municipal MTE, received for the transportation of passengers, reflected depending on the quality of road transport services to the population.

Private enterprises engaged in regional transport services are profitable. Therefore, the objective function for them will look different:

$$
\left\{\begin{array}{l}
S_{a} \rightarrow \max \\
K \geq K_{\text {min }}
\end{array},\right.
$$

where $K$ is the level of transport services for passengers provided by private carriers;

$K_{\min }$ is the minimum acceptable level of transport services for the population of the city (region);

$S$ is the business value of a transport company.

Based on this formula, the optimal passenger transport provision for municipal carriers and for commercial MTE will differ significantly. However, it must match the target function. [13].

\section{ANALYSIS}

We will formulate the most significant private indicators that reflect the quality of passenger transport services. To do this, we will interview specialists of the city transport Department, heads of the MTE and consumers of motor transport services themselves.

To conduct this survey, it is necessary to develop an appropriate questionnaire, in which respondents are asked to choose from a variety of factors, six main ones that, in their opinion, have a decisive influence on the level of quality of road transport services.

These factors were noted the following number of times: total time spent on the trip-89; relative level of fares-84; traffic density-77; emergency traffic safety-75; frequency of public transport - 73; number of transfers per trip-68; speed of the vehicle - 66; degree of filling of the cabin - 64, regularity of the vehicle - 61; environmental safety of transport - 57; reliability of the vehicle -51 ; the level of information service -42 times.

Local indicators and factors determining the level of quality of transport services for the region's population are as follows.

1. Total time spent traveling $\left(F_{1}\right)$ in a region. This local indicator is influenced by a number of factors:

- Density of the route network $\left(n_{11}\right)$ is defined as the ratio of the total length of streets and roads along which the routes of urban passenger transport go to the area of the city (region). Based on the density of the route network, it is possible to determine how well the entire population of the studied city (region) or a specific district of the city is provided with transportation.

- Frequency of movement $\left(n_{12}\right)$ is defined as the ratio of the number of vehicle movements along a specific route for a specific time interval.

- $\quad$ The average number of transfers per trip $\left(n_{13}\right)$.

After analyzing the three factors described above, it can be concluded that certain changes in the existing route network of urban public transport are necessary to reduce the travel time. One can also create new routes for public transport, or vice versa, decide to cancel existing ones if the route network is too dense.

2. Comfort conditions during the trip $\left(F_{2}\right)$. The value of this indicator depends on values of the following factors:

- The degree of filling the vehicle compartment $\left(n_{21}\right)$ is defined as the number of passengers per $1 \mathrm{~m}^{2}$ of the vehicle compartment.

- $\quad$ The average number of transfers per trip $\left(n_{22}\right)$.

3. Safety $\left(F_{3}\right)$. To assess the degree of traffic safety, two factors are used.

- Environmental safety $\left(n_{31}\right)$ is defined as the share of urban passenger transport in the total atmospheric emissions of pollutants. 
- Emergency traffic safety $\left(n_{32}\right)$ is estimated by the level of traffic accidents caused by vehicles, including those with a fatal outcome per 1,000,000 passengers.

4. The rhythm of urban public transport $\left(F_{4}\right)$. The following factors can be used as evaluation criteria.

- Frequency of movement $\left(n_{41}\right)$ is calculated as the ratio of the actual number of completed trips to the number of scheduled ones.

- The frequency of public transport $\left(n_{42}\right)$ is defined as the ratio of the number of transport movements on a specific route for a certain time interval. [13]

5. Cost indicator $\left(F_{5}\right)$ is defined as the share of the level of tariffs in urban public transport $\left(n_{52}\right)$ in relation to the cost of living.

In order to calculate integral indicator $K$, it is suggested to use the following formulas:

$$
\begin{gathered}
K=\sum_{i=1}^{5} \alpha_{i} \times F_{i}, \\
F_{i}=\sum_{j=1}^{m} \beta_{i j} \times \kappa_{i j},
\end{gathered}
$$

where $K$ is integral indicator of the level of public transport services;

$F_{i}$ is the i-th local indicator reflecting the level of quality of passenger transport services;

$\kappa_{i j}$ is the indicator showing the level of compliance of the above factors with their optimum;

$\alpha_{i}, \beta_{i j}$ are specific shares of indicators of each indicator $P_{i}$ and $\kappa_{i j}$ respectively, we expect the statistical method of analysis of hierarchies:

$$
\sum_{i=1}^{n} \alpha_{i}=1, \sum_{j=1}^{m} \beta_{i j}=1 .
$$

where $m$ is the number of quality factors.

Indicator $\kappa_{i j}$ is proposed to calculate:

- for those quality factors whose increase in value has a positive effect on the level of quality of transport services

$$
\kappa_{i j}=\frac{n_{i j}}{n_{i j}^{\ni}}
$$

where $n_{i j}^{\ni}$ is the maximum value of the $\mathrm{j}$-th factor for the analyzed period (standard).

- for those quality factors whose increase in value has negative affects on the level of quality of passenger transport services:

$$
\kappa_{i j}=\frac{n_{i j}^{\ni}}{n_{i j}},
$$

where $n_{i j}^{\ni}$ is the minimum value of the $\mathrm{j}$-th factor for the analyzed period (standard).

$\kappa_{i j} \rightarrow 1$ in the analyzed period, therefore $F_{i} \rightarrow 1$. The value of indicators $\kappa_{i j}=1$ and $F_{i}=1$ is not a limit, since in the future, as a result of effective management of the passenger transport service system, the values of factors $n_{i j}$ can improve and exceed the reference values, then $\kappa_{i j}>1$ and $F_{i}>1$. [6]

The higher the value of integral indicator $\mathrm{K}$, the more the created conditions for transport services for the population of the city (region) correspond to ideal ones.

\section{CONCLUSION}

The method proposed in the article is relevant in modern conditions of management in the market of motor transport services. It takes into account the goals and interests of all its participants, and reflects the main indicators that affect the choice of a vehicle by a passenger. Therefore, the assessment of these indicators is important for all carriers providing transport services, as competition in this market is currently increasing. At the same time, these indicators are important for municipalities because they must provide the necessary level of quality of transport services for the population [13].

The developed method increases the objectivity of assessing the level of quality of transport services due to the fact that an integral indicator of the quality of automobile passenger transport is used.

\section{References}

[1] K. Andreev, V. Terentyev, "Development of strategies for the development of urban passenger transport in EurAsEC countries" [E3S Web of Conferences], 135, 02013, 2019, DOI: 10.1051/e3sconf/201913502013

[2] Y.M. Sokolinskaya, "Model of interaction of the state and small entrepreneurship", Proc. of the Voronezh State Univer. of Engineer. Technol., vol. 81, no. 1, pp. 449-456, 2019, Retrieved from: https://doi.org/10.20914/2310-1202-2019-1-449-456

[3] A.A. Gazhur, I.N. Lukiyanchuk, "Trends of development of the sphere of services in Russia", Proc. of the Voronezh State Univer. of Engineer. Technol., vol. 80, no. 3, pp. 444-450, 2018, Retrieved from: https://doi.org/10.20914/2310-1202-2018-3-444-450

[4] K. Andreev, A. Kildishev, V. Terentyev, A. Shemyakin, "Safety assessment of road junctions by computer simulation", Bull. of transp. Inform., vol. 1, no. 283, pp. 20-23, 2019.

[5] J.V. Narolina, T.V. Sabetova, N.V. Shabutskaya, N.V. Gryshchenko, "The influence of innovative development on economic security of the region", Proc. of the Voronezh State Univer. of Engineer. Technol., vol. 81, no. 1, pp. 457-463, 2019, Retrieved from: https://doi.org/10.20914/2310-1202-2019-1-457-463

[6] S. Dorokhin, V. Terentyev, K. Andreev, Road safety: problems and solutions", World of Transp. and Technol. Mach., no. 2, pp. 67-73, 2017.

[7] V. Kiselev, A. Shemyakin, S. Polischuk, V. Terentyev, K. Andreev, D. Churilov, "Optimization of transport infrastructure of cities", Transp. Busin. in Russ., no. 5, pp. 138-140, 2018.

[8] N.N. Muraveva, N.S. Talalaeva, "The assessment of target value of performance indicators of small and medium-sized companies' financial management with industry and regional environmental features", Proc. of the Voronezh State Univer. of Engineer. Technol., 
vol. 81, no. 2, pp. 290-300, 2019, Retrieved from: https://doi.org/10.20914/2310-1202-2019-2-290-300

[9] M.S. Asmolova, S.V. Dedov, "The algorithm to ensure and implement the strategy of the effective management of innovation processes", Proc. of the Voronezh State Univer. of Engineer. Technol., vol. 80, no. 4, pp. 436-440, 2018, Retrieved from: https://doi.org/10.20914/2310$1202-2018-4-436-440$

[10] V. Konkina, A. Shemyakin, I. Babkin, "Information and software of managing the industry cluster of the region”, pp. 8632-8637, 2019 [Proc. of the 33rd Int. Business Information Management Association Conference, IBIMA 2019: Education Excellence and Innovation Management through Vision 2020].

[11] Y.P. Anisimov, Y.V. Zhuravlev, I.V. Kuksova, E.I. Balabanova, A.Y. Zhilnikov, T.V. Elagina, "Spatial analysis of the development of innovative potential of enterprises", Proc. of the Voronezh State Univer. of Engineer. Technol., vol. 81, no. 1, pp. 391-396, 2019, Retrieved from: https://doi.org/10.20914/2310-1202-2019-1-391-396

[12] N.N. Kudryavtseva, Y.V. Pakhomova, Y.N. Duvanova, "The concept of management development management enterprise", Proc. of the Voronezh
State Univer. of Engineer. Technol., vol. 81, no. 1, pp. 429-433, 2019 , Retrieved from: https://doi.org/10.20914/2310-1202-2019-1-429-433

[13] N.A. Konycheva, A.B. Martynushkin, K.P. Andreev, V.V. Terentyev, "Methodology for assessing the quality level of road transport services", Bull. of Transp. Inform., vol. 6, no. 288, pp. 22-26, 2019.

[14] K. Andreev, V. Terentyev, "Passenger transportation and optimization of the city route network", World of Transp., vol. 15, no. 6(73), pp. 156-161, 2019.

[15] T.A. Nekrasova, "Problems of optimizing the quality of life in modern Russia through the prism of economic theory and practice", Proc. of the Voronezh State Univer. of Engineer. Technol., vol. 80, no. 3, pp. 386-391, 2018, Retrieved from: https://doi.org/10.20914/2310-1202-2018-3-386$391 /$

[16] N. Byshov, A. Simdiankin, I. Uspensky, "Method of traffic safety enhancement with use of RFID technologies and ITS implementation", Transportat. Res. Proc., pp. 107-111, 2017, DOI: 10.1016/j.trpro.2017.01.030 